ALBORNOZ ADOLFO - Memoria y reconstrucción de escena: Gustavo Meza y la dramaturgia chilena posgolpe

\title{
Memoria y reconstrucción de escena: Gustavo Meza y la dramaturgia chilena posgolpe ${ }^{1}$
}

Memory and scene reconstruction: Gustavo Meza and the post-coup Chilean playwriting

\section{Adolfo Albornoz Farías ${ }^{2}$ UNIVERSIDAD AUSTRAL DE CHILE}

Resumen. En la escena teatral chilena posterior al golpe de Estado de 1973, destacan los trabajos dramatúrgicos Te llamabas Rosicler (1976) de Luis Rivano, Las tres mil palomas y un loro (1977) de Andrés Pizarro, El último tren (1978) de Gustavo Meza, Lo crudo, lo cocido, lo podrido (1978) de Marco Antonio de la Parra y Testimonio de las muertes de Sabina (1979) de Juan Radrigán. Estas piezas comparten al menos tres atributos clave: a) son las óperas primas teatrales de sus autores -los dos últimos, probablemente los principales referentes de la dramaturgia chilena del último medio siglo-; b) apelan de diversas formas a la escenificación de la memoria del Chile pregolpe para dar cuenta del arrasamiento sociocultural que conllevó el nuevo orden levantado por la dictadura; c) todas llegaron a escena dirigidas por Gustavo Meza quien en 1974 fundó la compañía (y luego la escuela) Teatro Imagen, la primera agrupación que emergió para resistir al autoritarismo desde los escenarios. Este artículo, entonces, enfatiza el trabajo con la memoria de Gustavo Meza - a partir de material testimonial mayormente inéditopara reconstruir algunos de los sentidos del quehacer teatral contestatario en ese momento crucial de la historia del teatro chileno, cuando la memoria misma devino fundamental como impulso creativo y como recurso dramatúrgico.

Palabras clave. Teatro chileno, Teatro y política, Memoria, Dictadura, Gustavo Meza.

Abstract. In the post-coup Chilean theatrical scene, there stand out the following scripts: Luis Rivano's Te llamabas Rosicler (1976), Andrés Pizarro's Las tres mil palomas y un loro (1977), Gustavo Meza's El último tren (1978), Marco Antonio de la Parra's Lo crudo, lo cocido, lo podrido (1978) and Juan Radrigan's Testimonio de las muertes de Sabina (1979). These works share at least three main features: a) they all are the theatrical debuts of its authors -the last two, probably the most important Chilean playwrights of the last half century-; b) they all stage, although in different ways, the memory of the pre-coup Chile to try to make sense of the social and cultural destruction carried out by the new order held by the military government; c) they all were directed by Gustavo Meza -who in 1974 founded the Teatro Imagen Company (and later the school of the same name), the first group that emerged to oppose authoritarianism from the stage. This paper emphasizes the work with Gustavo Meza's memory -from testimonial material yet unpublished- to reconstruct some of the senses that theatrical work had in this critical

\footnotetext{
${ }^{1}$ Artículo elaborado a partir del proyecto "Gustavo Meza: una historia testimonial y coral del teatro chileno", Folio 96379, financiado por el Fondo Nacional de Fomento del Libro y la Lectura, año 2015. Una versión preliminar de este artículo fue presentada, el 2 de septiembre de 2021, como conferencia inaugural de la línea de trabajo "Teatro, teatralidades y performance" del Núcleo de Sociología del Arte y las Prácticas Culturales de la Facultad de Ciencias Sociales de la Universidad de Chile. Agradezco a la Dra. Marisol Facuse, Directora del Núcleo, dicha invitación.

${ }^{2}$ Sociólogo y Director de Teatro. Licenciado en Sociología por la Universidad de Concepción. Doctor en Estudios de la Sociedad y la Cultura por la Universidad de Costa Rica. Realizó estudios de Teatro en la Universidad Finis Terrae y el Centro de Investigación Teatro La Memoria. Académico del Instituto de Lingüística y Literatura de la Facultad de Filosofía y Humanidades de la Universidad Austral de Chile. Mail: adolfo.albornoz@uach.cl
} 
moment of Chilean theatre history, when memory itself became crucial both as creative impulse and as dramatic content.

Keywords. Chilean Theatre, Theatre and politics, Memory, Dictatorship, Gustavo Meza. Introducción

El 11 de septiembre de 1973, con el golpe de Estado que derrocó al gobierno democrático constitucional encabezado por el presidente Salvador Allende, comenzó, junto con muchas otras historias, la historia del teatro chileno contemporáneo. La escena teatral profesional que tras décadas de trabajo había llegado a consolidarse a lo largo del país como parte de un proyecto de Estado comprometido con la ampliación del bienestar social -escena que hoy reconocemos como nuestro teatro moderno- y que consecuentemente fue hegemonizada por las compañías universitarias y algunos otros proyectos institucionales de carácter nacional, como ocurrió con el resto del campo cultural chileno, comenzó a ser desmantelada desde los primeros días de la dictadura. Las compañías fueron intervenidas y algunas clausuradas, las salas vieron restringido su funcionamiento, los repertorios padecieron la censura y la autocensura, los presupuestos fueron recortados o eliminados, muchos y muchas artistas quedaron desempleadas y no pocas ni pocos fueron apresados, torturados, exiliados o asesinados ${ }^{3}$.

Lidiando con el adverso horizonte cultural posgolpe, algunas agrupaciones teatrales independientes noveles en su identidad, esto es, nacidas después de 1973, pero lideradas por artistas de trayectoria, en su mayoría directores, trabajando junto a nuevos talentos, en especial autores, lograron primero reanimar, luego rearticular y finalmente renovar el panorama escénico chileno, dando así un resiliente origen a nuestro teatro contemporáneo. La dislocadora coyuntura nacional promovió la misma heterogénea e imprevista fusión más allá del tándem direccióndramaturgia. Ocurrió, por ejemplo, en los elencos, donde afloraron las y los estudiantes cuyos estudios teatrales se vieron truncados por los efectos del Golpe sobre las universidades del país, quienes procuraron completar su formación directamente arriba del escenario o alrededor de este, en espacios independientes, junto a actores y actrices de reconocido oficio.

Ejemplar dentro de este panorama resulta el quehacer del hasta ese momento director y profesor y desde entonces también dramaturgo y maestro de actuación, Gustavo Meza -y a partir de él de su compañía Teatro Imagen-. En 1973, contando con casi dos décadas de carrera como artista y académico, trabajaba en la Universidad de Chile (antes lo había hecho en la Universidad de Concepción). De la principal casa de estudios del país fue inmediatamente expulsado tras el golpe de Estado. Al año siguiente, en 1974, fundó Teatro Imagen, el primer colectivo nacido en dictadura, aventura en la que fue secundado por el ya experimentado actor Tennyson Ferrada y la todavía joven actriz Jael Unger. Con este núcleo de trabajo, entre 1976 y 1978, Meza llevó adelante una labor excepcionalmente fructífera en el marco del último medio siglo dramatúrgico chileno. Como director, estrenó las óperas primas de Luis Rivano, Te llamabas Rosicler (1976); de Andrés Pizarro, Las tres mil palomas y un loro (1977); de Marco Antonio de la Parra, Lo crudo, lo cocido, lo podrido (1978); y su propio primer trabajo como autor, El último tren (1978). Un año después dirigió también la ópera prima de Juan Radrigán, Testimonio de las muertes de Sabina (1979), aunque en este caso con la igualmente novel compañía Los Comediantes,

\footnotetext{
${ }^{3}$ Dadas las fuertes restricciones a la producción y circulación de información en Chile durante los primeros años de la dictadura, un buen registro de este traumático proceso, aunque fragmentado, lo ofrecieron las publicaciones en el exilio. Destaca la revista Araucaria de Chile, editada en Europa desde 1978, en cuyas páginas la cuestión teatral no estuvo ausente. Una mirada todavía temprana, pero ya más sistematizada, ofreció Grínor Rojo en Muerte y resurrección del teatro chileno, 1973-1983.
} 
ALBORNOZ ADOLFO - Memoria y reconstrucción de escena: Gustavo Meza y la dramaturgia chilena posgolpe

organizada en 1976 por la ya entonces célebre Ana González -quien en 1969 se había convertido en la primera actriz en la historia de Chile galardonada con el Premio Nacional de Artes-.

Así, durante la segunda mitad de los años setenta, resistiendo los embates de la dictadura, Gustavo Meza devino una figura protagónica de la escena teatral chilena como principal impulsor de una nueva generación de autores dramáticos -y prontamente también de una novísima camada de actores y actrices-, para quienes -siendo gravitante para esto el influjo de Meza, como demuestra el ejercicio sociológico artístico y biográfico aquí presentado- la memoria devino fundamental como impulso creativo y como recurso dramatúrgico ${ }^{4}$.

\section{Memoria como recurso: reconstruir una práctica de reconstrucción}

Hoy resulta evidente que cada uno de los dramaturgos que debutó vinculado al quehacer de Gustavo Meza terminó produciendo una obra de conjunto de rasgos distintivos. Rápidamente se asocian las piezas de Luis Rivano con la vida urbana en los bajos fondos, las obras de Juan Radrigán con la marginalidad socioexistencial y el teatro de Meza con la nostalgia -con tintes provincianos- por la patria perdida. La escritura de Marco Antonio de la Parra, el más complejo y difícil de encasillar entre los autores teatrales surgidos en esos años, ha transitado entre el cuestionamiento del imaginario republicano chileno, el asedio a la clase media nacional, la apropiación y resemantización posmoderna de la cultura occidental y la reflexión metateatral, entre otros motivos 5 .

No obstante, resulta igualmente pertinente notar la profunda afinidad temática que exhiben los textos inaugurales de estos autores. Todos debutaron apelando, aunque de maneras diversas, a la escenificación de la memoria del Chile anterior al golpe de Estado como respuesta al arrasamiento sociocultural emprendido por la dictadura. Todos, en resumen, debutaron poniendo la memoria "en escena".

Puesto que el análisis dramatúrgico intratextual no es el eje de este trabajo, a modo de ilustración de lo recién señalado, baste con reseñar un par de ideas fuerza. En Te llamabas Rosicler, la acción propuesta por Rivano y Meza ocurre justo una década antes del Golpe, en 1963, en la casa de una familia conservadora convertida en pensión, donde la propietaria, una mujer alguna vez acomodada y ahora rechazada por sus parientes por un desliz extramatrimonial con un estudiante universitario, se ve obligada a convivir con personajes clasemedieros y populares que poco a poco van ganando espacio dentro de la propiedad, subvirtiendo las jerarquías y normas establecidas, por lo que ella finalmente recurre a un guardia de seguridad, un oscuro habitante de la misma pensión, para que restaure el orden. En Las tres mil palomas y un loro, la trama dispuesta por Pizarro y Meza transcurre ya entrados los años sesenta, al interior de un matrimonio relativamente acomodado, donde la compleja voluntad de convivencia entre conservadurismo y rebeldía, burguesía e intelectualidad, no puede desembocar más que en

\footnotetext{
${ }^{4}$ La comprensión sociológica de la memoria aquí recurrida reconoce como basal el trabajo de Maurice Halbwachs, desde su fundacional volumen Los marcos sociales de la memoria (1925) hasta su póstuma publicación La memoria colectiva (1950).

5 Amplias aproximaciones a estas dramaturgias ofrecen las antologías -y sus correspondientes estudios introductorios- Antología de obras teatrales de Luis Rivano -prólogo de Juan Andrés Piña-, Crónicas del amor furioso de Juan Radrigán -prólogo de Adolfo Albornoz -, Murmuraciones acerca de la muerte de un juez y otras dos murmuraciones de Gustavo Meza -prólogo de Marco Antonio de la Parra- y El arte del peligro de Marco Antonio de la Parra -prólogo de Adolfo Albornoz-.
} 
infidelidad e inestabilidad. Así, estas y el resto de las piezas en cuestión buscaron en el pasado reciente y conocido claves que dieran sentido a un presente tan extraño como brutal.

Por otra parte, hoy es también evidente que tras fundar colectivamente la dramaturgia chilena posgolpe, cada uno de los autores teatrales aquí referidos trascendió en el campo cultural chileno con una huella singular. Entre las cumbres de su figuración destacan, entre muchísimos cargos y encargos, reconocimientos y premios, la incorporación a la Academia Chilena de Bellas Artes de Marco Antonio de la Parra en 1997 y de Gustavo Meza en 2007; y el otorgamiento del Premio Nacional de Artes, el mayor reconocimiento al que puede aspirar un artista chileno en su patria, al mismo Meza en 2007 y a Juan Radrigán en 2011 -galardón al que De la Parra fue un serio candidato este 2021. Muy significativos fueron también, en octubre de 2016, el velorio de Radrigán sobre el escenario del Teatro del Sindicato de Actores y Actrices de Chile y el homenaje que, camino a su funeral, recibió en el Teatro Nacional Chileno, a los que cientos de personas nos acercamos para decir adiós, mientras el gobierno decretó duelo oficial.

Sin perjuicio de lo anterior, corresponde observar lo estrechamente emparentados que estuvieron los primeros pasos dramatúrgicos de estos noveles autores mediante la impronta de Meza, puesto que a través de él dialogaron con una tradición teatral con la que muchos de ellos no tuvieron directa relación, pero procuraron rescatar y, quizás sin proponérselo, terminaron renovando. Privilegiando, entonces, el testimonio de Gustavo Meza, un protagonista clave de este y varios otros capítulos de la historia cultural de Chile, este artículo trabaja una memoria "de la escena".

Alejándose de la tematización intratextual que de la dramaturgia habitualmente hace la teoría literaria y/o teatral, el proyecto de investigación del que forma parte este artículo se acerca a la indagación de la sociología de la cultura y el arte, con acento en las condiciones de producción y énfasis en la perspectiva biográfica. Este proceso heurístico -por ejemplo, para cuestiones de recopilación, sistematización, análisis e interpretación de información- ha tenido presentes categorías como estructura de sentimiento, campo cultural y mundo del arte, elaboradas por Raymond Williams, Pierre Bourdieu y Howard Becker, respectivamente, a la vez que distinciones como relato de vida e historia de vida trabajadas por Daniel Bertaux. En este sentido, por último, cabe destacar que todos los fragmentos testimoniales que son citados a continuación provienen de entrevistas hasta ahora inéditas, realizadas (por el autor) a Gustavo Meza entre los años 2015 y $2018^{6}$.

\section{Reconstrucción: escena posgolpe y compañía Teatro Imagen}

La compañía Teatro Imagen, cofundada en 1974 por Gustavo Meza y liderada por él hasta hoy igual que la escuela homónima creada una década después, en 1984-, despuntó como parte de la primera cohorte de proyectos escénicos que, tras el golpe de Estado y la consiguiente dictadura, lograron articular un heterogéneo coro de voces disidentes o contestatarias ante el gobierno militar.

El Teatro Imagen compartió esta trinchera teatral, entre otros, con la ya mencionada compañía Los Comediantes, organizada en 1976, la compañía Teatro La Feria y el Taller de Investigación Teatral, ambos creados en 1977, también liderados por reconocidas figuras: Jaime

${ }^{6}$ Considérense, por ejemplo, Cultura y sociedad, 1780-1950: de Coleridge a Orwell de Raymond Williams; Marxismo y literatura de Raymond Williams; Campo de poder, campo intelectual: itinerario de un concepto de Pierre Bourdieu; Las reglas del arte: génesis y estructura del campo literario de Pierre Bourdieu; Los mundos del arte: sociología del trabajo artístico de Howard Becker y Los relatos de vida: perspectiva etnosociológica de Daniel Bertaux. 
ALBORNOZ ADOLFO - Memoria y reconstrucción de escena: Gustavo Meza y la dramaturgia chilena posgolpe

Vadell y Raúl Osorio, respectivamente; y el Teatro Ictus, nacido en 1956, decano del teatro independiente chileno, uno de los pocos grupos que sobrevivió a la intervención militar, por entonces liderado por Nissim Sharim y Delfina Guzmán ${ }^{7}$.

A propósito de la voluntad de memoria con que emergió el proyecto Teatro Imagen, Meza explica:

Fuimos la primera compañía de teatro que nació después del golpe de Estado, cuando

política y económicamente la lógica decía que era imposible hacer teatro. Pero lo conseguimos. Había que hacerlo. Éramos conscientes de que teníamos una responsabilidad: cuidar y traspasar una llama que se nos había entregado y que, por muchas que fueran las dificultades, no podíamos dejar que se apagara.

De acuerdo con este ethos, corresponde considerar que Meza, quien había iniciado sus estudios de teatro en la Universidad de Chile en 1954, su carrera como director teatral con la compañía de la Universidad de Concepción en 1957 y, tras varias otras experiencias artísticas y docentes, había regresado como profesor a su alma mater en 1969, fue el vector responsable de insuflar el compromiso con la tradición teatral chilena en los dramaturgos cuyas óperas primas estrenó, puesto que ninguno de ellos contaba con experiencia escénica profesional previa.

A partir del mismo testimonio, por otra parte, cabe observar que las adversas condiciones impuestas por la dictadura obligaron a los nuevos colectivos teatrales a idear novedosas relaciones e inéditos mecanismos para procurar su subsistencia económica y la seguridad de sus integrantes. Por ejemplo, algunos se acercaron a iglesias o se vincularon con organizaciones no gubernamentales (ONG) y redes de solidaridad internacional, mientras que otros apostaron por el capital social y simbólico de ciertas figuras. En el caso de la compañía Teatro Imagen, esta emergió contando con la solidaridad del Instituto Chileno Francés de Cultura y especialmente de Roland Husson, consejero cultural de la Embajada de Francia en Chile, quien apoyó decididamente el quehacer artístico y cultural durante los primeros años de la dictadura, a la vez que procuró refugio para numerosos y numerosas intelectuales y artistas que estaban en riesgo y se exiliaron en Francia ${ }^{8}$.

Sobre este decisivo vínculo fundacional institucional-binacional y la posibilidad que conllevó de reconstruir puentes con experiencias teatrales anteriores al Golpe, Meza evoca:

\footnotetext{
${ }^{7}$ Un registro imprescindible de este momento crucial de la historia del teatro chileno lo realizó el Centro de Indagación y Expresión Cultural y Artística (CENECA), donde María de la Luz Hurtado, Carlos Ochsenius y José Román, mediante el proyecto de investigación "Maneras de hacer y pensar el teatro en el Chile actual", publicaron la serie que incluyó los documentos de trabajo T.I.T.-Taller de Investigación Teatral; Teatro La Feria; Teatro Ictus y Teatro Imagen.

${ }^{8}$ Véase el libro testimonial Nos duele Chile de Roland Husson y la película documental Un diplomático francés en Santiago de Patricio Paniagua.
} 
En el Instituto Chileno Francés estaba Roland Husson, un tipo extraordinario. Ayudó muchísimo al mundo del arte y la cultura mientras estuvo en Chile. Por ejemplo, como en la universidad las clases de teatro estuvieron suspendidas, el Instituto prestó una sala en la que yo hice clases a los estudiantes que quisieron seguir formándose. Fue una experiencia importante para impedir que se perdiera por completo el trabajo que veníamos haciendo antes del Golpe y como semillero. Ahí se armó el grupo Teatro Joven, de donde salieron varios que habían sido mis alumnos en la universidad y después se sumaron a nuestra compañía. Por otro lado, el Chileno Francés facilitó la sala para un proyecto que empezó como una idea loca de un productor y terminó como la primera obra estrenada en dictadura: La mano y la gallina, con Tennyson Ferrada como protagonista y yo como director. Fue muy gratificante porque no aguantábamos más sin hacer teatro. Y parece que al público le pasaba lo mismo porque rápidamente llegamos a cien funciones, a pesar de que teníamos que hacer teatro en las tardes. Esa obra abrió la puerta para un reencuentro.

Aunque apoyos como el de Husson fueron vitales -así como de diplomáticos y diplomáticas suecos, alemanas, mexicanos, costarricenses y más-, nada garantizaban. De hecho, aunque la producción de La mano y la gallina de Fernando Josseau, estrenada durante el verano de 1974, constituyó un sorprendente éxito de público y de crítica, tras varios meses de funciones los otros dos integrantes del elenco, María Elena Duvauchelle y Julio Jung, partieron al exilio en Venezuela, donde permanecieron durante diez años. La represión política era, evidentemente, un grave problema; la crisis económica era otro también serio. Meza recuerda:

Estábamos sicológica y moralmente destruidos por lo que significaba sobrevivir trabajando en oficinas de publicidad, haciendo comerciales de televisión y otras estupideces por el estilo. Y estaban físicamente reventados los compañeros que tenían que hacer cualquier otro tipo de trabajo para subsistir. Eran tiempos muy duros. 
ALBORNOZ ADOLFO - Memoria y reconstrucción de escena: Gustavo Meza y la dramaturgia chilena posgolpe

La promisoria experiencia vivida con La mano y la gallina fue el catalizador que impulsó a Meza, Tennyson Ferrada y Jael Unger - por entonces compañera sentimental del director- a armar su propio grupo. De manera algo paradójica, la empresa de publicidad donde Meza trabajaba/sobrevivía otorgó un préstamo para financiar la primera producción.

La compañía Teatro Imagen debutó en noviembre de 1974 con el estreno de El día que soltaron a Joss del dramaturgo belga Hugo Claus y dobló su apuesta en junio de 1975 con Mi adorada idiota del dramaturgo francés Francois Boyer9. reflexiona:

En relación con este momento inaugural que también estuvo lleno de memoria, Meza

Actualizamos a las nuevas circunstancias la herencia que traíamos, no solo la formación técnica, sino también la ética: primero preguntarnos por qué y para qué hacer teatro en cada momento y en cada lugar y luego buscar cómo hacerlo. Así me formé en la Universidad de Chile y así trabajamos a fondo en la Universidad de Concepción, donde se dio uno de los movimientos teatrales más importantes de la historia, de donde Tennyson y yo derivábamos directamente. Allá, en el sur, habíamos desarrollado un proyecto de verdadero teatro nacional y popular tanto en el lenguaje escénico como en la difusión del trabajo, un teatro muy efectivo escénicamente, que logramos ligar a un enorme público laboral y estudiantil. Entonces, La mano y la gallina, por una parte nos demostró que había un público huérfano ávido de teatro que primero teníamos que recuperar y después ampliar. Y por otra parte reafirmó la urgente necesidad de reaccionar ante la frivolidad. A veces se olvida que entre las aberraciones de la dictadura también estuvo la campaña de verdadera idiotización nacional que llevó adelante. Nosotros queríamos hacer un teatro que entretuviera ojalá a mucha gente y también la hiciera pensar. Y para esto el

\footnotetext{
${ }^{9}$ Aunque la compañía y la escuela Teatro Imagen son referencias obligadas en los trabajos panorámicos sobre el teatro chileno de las últimas décadas, el corpus monográfico sobre ellas es escaso. Destacan Teatro Imagen, documento de trabajo -ya indicado- de María de la Luz Hurtado y José Román; Os processos criativos na trajetória inicial da compañía Teatro Imagen, 1974-1984, tesis de maestría de Paula González; y 40 anos de Teatro Imagen. Redes e trajetórias, influencias artísticas e pedagógicas no teatro chileno, tesis de doctorado de Paula González.
} 
teatro de Francia y sus alrededores, que conocíamos bien porque siempre estuvo presente en los repertorios de los teatros universitarios chilenos, nos parecía ideal ${ }^{10}$.

\section{Óperas primas inaugurales de la dramaturgia chilena posgolpe}

El reencuentro entre los y las profesionales de la escena y su público fue un proceso gradual y complejo a lo largo de todo el país durante los momentos inmediatamente posteriores al golpe de Estado. De hecho, el primer estreno de la compañía Teatro Imagen tuvo pocos espectadores y fue un fracaso económico, situación que solo mejoró parcialmente con la segunda producción. Más rápida fue la complicidad que la emergente agrupación encontró en otros agentes del mundo artístico-cultural. Por ejemplo, parte de los y las estudiantes de teatro cuya formación había sido interrumpida por la intervención militar e informalmente atendida por Gustavo Meza, le retribuyeron asumiendo como voluntarios tareas de producción. A la vez, colegas que continuaban en la Universidad de Chile y otras instituciones, a título personal y de manera cuasi clandestina, hacían llegar a las y los integrantes de Imagen materiales reutilizables para sus proyectos. El Instituto Chileno Francés de Cultura, por su parte, propuso a la compañía un convenio formal de colaboración. Sobre este decisivo momento, Meza comenta:

Roland Husson elaboró un plan: difundir nosotros la cultura francesa y proteger ellos en alguna medida la cultura nacional. A nosotros nos interesaba seguir en la línea de los franceses. Sentíamos que con la obra de Joss habíamos podido remover el inconsciente al poner en escena una reflexión sobre la culpa. Con la de Boyer hablábamos de una isla que se estaba hundiendo y lo que implicaba que cada uno buscara individualmente su tabla de salvación. Más de alguien dijo que habíamos alterado el texto, pero no fue así. En ese momento solo nos interesaban problemáticas generales que quizás sutilmente pudieran ser asociadas con la contingencia. Estábamos convencidos de que nuestro compromiso con el país y la cultura se expresaba, en primer lugar, al decidir quedarnos en Chile y formar un compañía, a pesar de los riesgos que corríamos y los ofrecimientos que recibimos para exiliarnos -empezando por el mismo Husson y los franceses- y, en segundo lugar, al decidir

${ }^{10}$ El trabajo de Gustavo Meza, Tennyson Ferrada y tantos y tantas más como integrantes del Teatro de la Universidad de Concepción -experiencia esencial para Meza dentro de sus casi siete décadas de ininterrumpido trabajo teatral- ha sido reconstruido por Marta Contreras, Patricia Henríquez y Adolfo Albornoz en Historias del Teatro de la Universidad de Concepción, TUC. 
ALBORNOZ ADOLFO - Memoria y reconstrucción de escena: Gustavo Meza y la dramaturgia chilena posgolpe

montar de la mejor forma las obras que pudiéramos hacer con nuestros escasos recursos y nuestro reducido elenco. Pensábamos que no era el momento para grandes planteamientos políticos ni estéticos y tampoco para mirar atrás o analizar la tragedia nacional, así que decidimos seguir con la dramaturgia francesa y dejar la chilena para más adelante. Sí nos propusimos que nuestras obras estuvieran muy bien hechas, que las actuaciones fueran impecables. Queríamos que la gente sintiera que estaba frente a muy buenos actores, que viera que en Chile había muy buenos actores y pensara que era un crimen que no estuvieran haciendo su trabajo o, peor aún, yéndose del país. También pensábamos, un poco ingenuamente, que este reconocimiento nos daría algo de seguridad porque podía ser más difícil tocar a figuras queridas. Nos habíamos dado cuenta de que la publicidad y la televisión podían ayudarnos más allá de lo económico porque, si bien cualquiera podía desaparecer de un día para otro, quizás quien era rostro de una campaña publicitaria grande o trabajaba en una teleserie tenía menos probabilidades de que le pasara algo. Lamentablemente, esta posibilidad no era la misma para todos. Mientras Jael protagonizaba una teleserie en el Canal 13, Tennyson fue uno de los primeros actores vetados en el Canal 7. En la televisión y en nuestro gremio hubo listas negras, esto nadie lo puede negar.

El objetivo de producir trabajos de excelencia fue logrado desde el primer momento. Tennyson Ferrada recibió el Premio de la Crítica al Mejor Actor por el estreno de 1974, El día que soltaron a Joss; Jael Unger obtuvo el Premio de la Asociación de Periodistas de Espectáculos a la Mejor Actriz por la producción de 1975, Mi adorada idiota, y ambos continuaron recibiendo los mismos reconocimientos $\mathrm{u}$ otros afines, especialmente Ferrada, por varios de los estrenos siguientes.

Sin embargo, el deseo de postergar la incursión en la dramaturgia chilena no pudo ser satisfecho. Mientras la compañía Teatro Imagen preparaba su tercera puesta en escena, los dramaturgos y dramaturgas franceses se unieron para, como medida de solidaridad y presión ante la dictadura chilena, prohibir la presentación de sus obras en nuestro país. La pieza que ya se 
encontraba en proceso de ensayos debió ser desechada y en el marco del convenio con el Instituto Chileno Francés de Cultura la única otra opción era la dramaturgia chilena.

En 1976, entonces, Te llamabas Rosicler de Luis Rivano se convirtió en el tercer estreno de la compañía y en el primer impulso para una nueva generación de dramaturgia nacional. A propósito de este nuevo paso hacia adelante que una vez más estuvo lleno de pasado perviviendo en el presente, Meza explica:

Cuando los autores franceses negaron los permisos para hacer sus obras, se nos vino la realidad encima. Dijimos, bueno, se hace una obra chilena. Y si la obra que necesitamos no está, la inventamos. Era lo mismo que Pedro de la Barra había repetido y practicado durante años, desde los inicios del Teatro Experimental de la Universidad de Chile. Él planteaba que sin dramaturgos nacionales no podía haber un verdadero teatro nacional y que si los autores no aparecían, las compañías tenían que inventarlos. Esto lo vivimos directamente cuando Pedro tuvo la idea de juntar en Concepción a Manuel Rojas con Isidora Aguirre para que escribieran Población Esperanza, y cuando luego se esforzó por hacer aparecer un texto de autor local: Las redes del mar de José Chesta. Entonces, como Teatro Imagen llevábamos un par de años conversando sobre ideas y temas para cuando estuviéramos listos para montar teatro chileno y de pronto nos encontramos con esta urgencia: teníamos que salvar la compañía y no podíamos sentarnos a esperar que un dramaturgo escribiera una obra, sino que teníamos que trabajarla nosotros. Conversamos nuestras ideas con varios novelistas, cuentistas, poetas y Luis Rivano quedó primero en la lista. Él nos hizo una propuesta de vuelta y comenzamos a trabajarla colectivamente.

Así nació el enorme éxito de público y de crítica que fue Te llamabas Rosicler, pieza que, además, sin haberlo buscado, abrió el camino para dialogar más directamente con los acontecimientos nacionales del momento. Como el compromiso con el Instituto Chileno Francés seguía en pie y la negativa de los autores y autoras teatrales franceses a ser estrenados en Chile también, la compañía recurrió a un dramaturgo ya muerto. Ese mismo año estrenaron Topaze de Marcel Pagnol. Y al siguiente, en 1977, se arriesgaron con un segundo texto chileno: Las tres mil 
ALBORNOZ ADOLFO - Memoria y reconstrucción de escena: Gustavo Meza y la dramaturgia chilena posgolpe

palomas y un loro de Andrés Pizarro, quien, como Rivano, había incursionado en otros géneros antes, pero no en la dramaturgia. Comenta Meza:

En nuestra urgencia por hacer teatro chileno y buscar autores, para nosotros era importante tratar de incorporar a un hombre como Andrés Pizarro al teatro. Fue un enorme desafío que nos autoimpusimos, pero no resultó. El trabajo no quedó bien y fue un merecido fracaso económico y de crítica.

Tras llevar a escena esa misma temporada otra pieza francesa, El visitante y la viuda de Víctor Haim, en 1978 la compañía arremetió con un nuevo drama nacional: El último tren, escrito por Gustavo Meza en colaboración con los integrantes del Teatro Imagen, proceso creativo en el que terminaron de afinar una metodología propia para la producción de dramaturgia original.

A continuación, el director condujo los debuts de quienes se convertirían en dos autores mayores - probablemente los dos principales referentes de la dramaturgia chilena del último medio siglo-: Lo crudo, lo cocido, lo podrido de Marco Antonio de la Parra, preestrenada, censurada y estrenada en 1978, y Testimonio de las muertes de Sabina de Juan Radrigán, escenificada en 1979 -cada una de las cuales, como clásicos del teatro chileno, merece ser revisitada por separado, tanto por su densidad textual como por su trascendencia como obra matriz de una producción de conjunto ${ }^{11}$.

\section{Estrenar en dictadura: otras voces}

En el marco del ejercicio de memoria que este artículo nos propone, cabe volver brevísimamente sobre las óperas primas de Radrigán y De la Parra y en relación con este último recordar un singular episodio a fin de relevar desde otras perspectivas el quehacer de Gustavo Meza.

El año 1978, cuando el director Eugenio Dittborn estaba a la cabeza del Teatro de la Universidad Católica, procuró incorporar a esta institución al proceso de promoción de esa nueva generación de dramaturgia chilena que Meza e Imagen, secundados por el Teatro La Feria, el Taller de Investigación Teatral y el Teatro Ictus, entre otras compañías independientes, esforzada y arriesgadamente venían impulsando hacía un par de años ${ }^{12}$.

Dittborn propuso que la compañía universitaria estrenara Lo crudo, lo cocido, lo podrido, de un novel y todavía desconocido dramaturgo, Marco Antonio de la Parra, y encargó a Meza, ya no solo director, sino también formador de nuevos autores, la responsabilidad de la puesta en escena. Tras meses de trabajo, con afiches impresos, invitaciones cursadas y prensa desplegada,

\footnotetext{
${ }^{11}$ Miradas panorámicas a la escritura dramática del período -que incluyen estos y otros autores- brindan las antologías críticas Teatro chileno de la crisis institucional, 1973-1980 de María de la Luz Hurtado, Carlos Ochsenius y Hernán Vidal; Teatro y dictadura en Chile de Elba Andrade y Walter Fuentes, y Un siglo de dramaturgia chilena, 1910-2010. Tomo III: 1973-1990, creatividad y resistencia en tiempos adversos de María de la Luz Hurtado y Mauricio Barría.

${ }^{12}$ Estos otros colectivos, sin embargo, apostaron mucho más por una línea de trabajo dramatúrgico paralela a la desarrollada por Imagen y tematizada en este artículo: la creación colectiva.
} 
llegaron los ensayos generales. Jorge Sweet, oficial de la armada, ejercía como rector delegado de la Pontificia Universidad Católica de Chile. Su vicerrector de Comunicaciones era Hernán Larraín, actual ministro de Justicia. Tras un ensayo general que consistió en una función privada para autoridades del Teatro y la Universidad, Larraín se acercó a Dittborn, le dijo "No", y se retiró sin decir más. Y así una producción que estaba lista para iniciar su temporada en los días siguientes fue censurada.

Ante las cámaras de Canal 13, el mismo Larraín -quien al año siguiente sería promovido a vicerrector académico- explicó:

Lo crudo, lo cocido, lo podrido no ha constituido, en opinión de las autoridades superiores de esta universidad, un ejemplo de progreso cultural. Por el contrario, dado su lenguaje, dada cierta irreverencia sostenida a lo largo del desarrollo dramático de esta obra, creemos que está muy lejos del nivel que ha tenido en sus treinta y cinco años el teatro de nuestra universidad. Hemos creído conveniente, en consecuencia, suspenderlo [el estreno] por cuanto el nivel que nosotros aspiramos a tener es de excelencia. No aceptamos cosas medias y mucho menos vulgares, groseras o que se presten para finalmente casi insultar al público que pudiera asistir a ver esta obra $\left(\text { Mierda } 47^{\prime} 25^{\prime \prime}\right)^{13}$.

El resto de la historia es sobradamente conocido. Tras este frustrado reencuentro con la escena universitaria, Meza volvió a su trinchera en el teatro independiente, desde donde decidió insistir en el proyecto. Así, con un elenco reforzado para la ocasión con ex compañeros del Teatro de la Universidad de Concepción -a Tennyson Ferrada, Jael Unger y Gonzalo Robles se sumaron Fernando Farías y Alberto Villegas-, la compañía Teatro Imagen desafió el autoritarismo y estrenó Lo crudo, lo cocido, lo podrido apenas unos meses después de haber sido censurada como producción de la Universidad Católica ${ }^{14}$.

\footnotetext{
${ }^{13}$ Mierda mierda, la función debe continuar, serie documental de seis capítulos dirigida por Daniel Uribe, es un interesante y reciente trabajo de investigación-divulgación audiovisual a propósito del contexto de lo que este artículo aborda. La declaración aquí reproducida proviene del capítulo 2, dedicado al teatro de resistencia durante la dictadura.

${ }^{14}$ Los riesgos no eran pocos. Apenas un año antes, a inicios de 1977, cuando la compañía Teatro La Feria llevaba pocos días de exitosas funciones de su primer trabajo, Hojas de Parra, salto mortal en un acto, con dramaturgia de José Manuel Salcedo y Jaime Vadell sobre textos de Nicanor Parra y dirección de Jaime Vadell, la carpa de circo en la que se presentaban fue quemada. Esto ocurrió en Providencia, durante la madrugada, en medio del toque de queda. Nunca se determinaron culpables ni se entregó una versión oficial de los hechos. Pocos días antes, el periódico $L a$ Segunda, titulaba en portada: "Infame ataque al gobierno" y en su interior incluía un escandalizado y extenso artículo sin firma titulado "Obra teatral critica política del gobierno". Véase "40 años de Hojas de Parra, la obra que acabó entre las llamas" de Pedro Bahamondes.
} 
ALBORNOZ ADOLFO - Memoria y reconstrucción de escena: Gustavo Meza y la dramaturgia chilena posgolpe

En 1979, contrariando la opinión del entonces vicerrector y actual ministro Larraín, a quien la propuesta de la dupla De la Parra/Meza le pareció "vulgar", "grosera" y de bajo "nivel", opiniones que consideró argumentos suficientes para prohibir la presentación, el nuevo texto dramático recibió el Premio Latin American Theatre, en Nueva York.

A propósito de la decisiva experiencia que como novel dramaturgo De la Parra vivió junto a Meza como director-formador, en una crónica sobre su prehistoria dramatúrgica, el autor comentó:

Hice una y otra versión hasta lograr lo que Gustavo consideró un material de trabajo... Con él aprendía a cada momento algo nuevo que me iba iluminando lo que significaba, realmente, ser dramaturgo (Obscenamente 30).

Algunos años más tarde, al prologar una antología de textos de Meza, De la Parra agregó:

Junto a él [Gustavo], en largas sesiones de lectura y discusión, paseos peripatéticos, ensayos meticulosos, fui entendiendo de qué se trataba esto de la dramaturgia. Escribí con su mirada de padre por encima de mi hombro, dejando que yo me manifestara en toda mi plenitud (Prólogo 5).

Finalmente, en una entrevista del año 2001, De la Parra precisó:

Gustavo me hace entender lo que significa el arte de la escritura, y lo hace de una forma muy bonita; él nunca me enseñó a escribir, sino que estrujó mi propia forma de hacerlo (Guerrero, "Marco" 69).

Radrigán, por su parte, con la simpleza y contundencia que caracterizan sus palabras, a propósito de su experiencia escénica originaria, en una entrevista del mismo año 2001, explicó:

Después [del golpe de Estado] me pasaron muchas cosas; en una de esas terminé vendiendo libros en un puesto de la Plaza Almagro, donde escribí mi primera obra. Se la mostré a Tennyson Ferrada y él a Gustavo Meza, quien la montó de inmediato. La 
obra era Testimonio de las muertes de Sabina. Entonces, si no hubiese existido la gestión de Tennyson y de Gustavo, yo no habría escrito más (Guerrero, Juan 142).

\section{Final: brevísima contextualización histórico-dramatúrgica}

Para terminar de aquilatar la importancia y trascendencia del trabajo artístico y cultural de Gustavo Meza revisado en estas páginas, ténganse presentes los siguientes datos.

La dramaturga Isidora Aguirre, figura esencial del teatro chileno y en particular del movimiento de los teatros universitarios y la dramaturgia de crítica social, estrenó en 1969 Los que van quedando en el camino. Al momento del golpe de Estado trabajaba en la Universidad Técnica del Estado, de donde evidentemente tuvo que salir. Recién vino a producir una nueva obra mayor en 1982: Lautaro: epopeya del pueblo mapuche.

Egon Wolff, otra figura clave del teatro chileno pregolpe, estrenó en 1970 Flores de papel. Durante los años setenta reestrenó esta pieza en Argentina, Inglaterra y Francia y recién volvió a presentar un nuevo texto en la escena nacional en 1984: La balsa de la medusa.

Alejandro Sieveking, otro nombre propio fundamental del teatro chileno, los teatros universitarios e incluso de la escena nacional del siglo XXI, para el 11 de septiembre de 1973, junto a su compañía, el Teatro del Ángel, ensayaba La virgen del puño cerrado bajo la dirección de Víctor Jara. Tras el brutal asesinato de su compañero, el autor asumió la puesta en escena y algunos meses más tarde estrenaron, aunque con un nuevo y atenuado título: La virgen de la manito cerrada. A continuación partieron al exilio, estuvieron en Costa Rica durante diez años y Sieveking volvió a estrenar una nueva pieza en Chile recién en 1985, tras su retorno: La comadre Lola.

Por otra parte, Ramón Griffero, figura clave del underground y de la segunda generación de autores y autoras que surgieron durante la dictadura, estrenó su primer trabajo en Chile -tras haberse formado en Europa- en 1982: Recuerdos del hombre con su tortuga.

¿Qué ocurrió en términos dramatúrgicos autorales - más allá de la creación colectivaentre el golpe de Estado de 1973 y esta serie de reapariciones y emergencias ya entrados los años ochenta? En buena medida, lo que aquí ha sido explicado: un proceso de rearticulación de la escena teatral chilena que encontró en la memoria uno de sus primordiales recursos y tuvo a la promoción de una nueva generación de dramaturgos como uno de sus principales productos; proceso que aquí ha sido reconstruido trabajando la memoria de uno de sus mayores protagonistas, Gustavo Meza. 
ALBORNOZ ADOLFO - Memoria y reconstrucción de escena: Gustavo Meza y la dramaturgia chilena posgolpe

\section{Bibliografía}

Albornoz, Adolfo. "Prólogo: Juan Radrigán: veinticinco afanosos años entre textos y escenas". Crónicas del amor furioso. Juan Radrigán. Santiago: Frontera Sur, 2004. 7-15. Impreso.

---. "Prólogo: Marco Antonio de la Parra: tres décadas de teatro". El arte del peligro. Marco Antonio de la Parra. Santiago: Frontera Sur, 2007. 9-28. Impreso.

---. "Entrevistas con Gustavo Meza". 2015-2018. Inéditas.

Andrade, Elba y Fuentes, Walter. Eds. Teatro y dictadura en Chile: Antología crítica. Santiago: Documentas, 1994. Impreso.

Araucaria de Chile. 1978-1990. http://www.memoriachilena.gob.cl/602/w3-article-92254.html

Bahamondes, Pedro. "40 años de Hojas de Parra, la obra que acabó entre las llamas". La Tercera. 10 feb. 2017. https://www.latercera.com/noticia/40-anos-hojas-parra-la-obraacabo-las-llamas/

Becker, Howard. Los mundos del arte: Sociología del trabajo artístico. Bernal: Universidad Nacional de Quilmes, 2008 [1982]. Impreso.

Bertaux, Daniel. Los relatos de vida: Perspectiva etnosociológica. Barcelona: Edicions Bellaterra, 2005 [1997]. Impreso.

Bourdieu, Pierre. Campo de poder, campo intelectual: Itinerario de un concepto. Tucumán: Montressor, 2002 [1966-1980]. Impreso.

---. Las reglas del arte: Génesis y estructura del campo literario. Barcelona: Anagrama, 1995 [1992]. Impreso.

Contreras, Marta, Patricia Henríquez y Adolfo Albornoz. Historias del Teatro de la Universidad de Concepción, TUC. Concepción: Universidad de Concepción, 2003. Impreso.

González, Paula. "Os processos criativos na trajetória inicial da compañía Teatro Imagen, 19741984”. Tesis de Maestría. Universidade Estadual de Campinas. 2011. Impreso.

---. "40 anos de Teatro Imagen: Redes e trajetórias, influencias artísticas e pedagógicas no teatro chileno". Tesis de Doctorado. Universidade de Sao Paulo. 2015. Impreso.

Guerrero, Eduardo. "Marco Antonio de la Parra". Acto único: Dramaturgos en escena. Santiago: RIL, Universidad Finis Terrae, 2001. 61-74. Impreso.

---. “Juan Radrigán”. Acto único: Dramaturgos en escena. Santiago: RIL, Universidad Finis Terrae, 2001. 137-155. Impreso.

Halbwachs, Maurice. Los marcos sociales de la memoria. Barcelona y Concepción: Anthropos, Universidad de Concepción, 2004 [1925]. Impreso.

---. La memoria colectiva. Zaragoza: Prensas Universitarias de Zaragoza, 2004 [1950]. Impreso.

Hurtado, María de la Luz y Carlos Ochsenius. T.I.T.-Taller de Investigación Teatral. Santiago: CENECA, 1979. Impreso.

---. Teatro La Feria. Santiago: CENECA, 1980. Impreso.

---. Teatro Ictus. Santiago: CENECA, 1980. Impreso.

Hurtado, María de la Luz, Carlos Ochsenius y Hernán Vidal. Eds. Teatro chileno de la crisis institucional, 1973-1980: Antología crítica. Santiago: University of Minnesota, CENECA, 1982. Impreso.

Hurtado, María de la Luz y José Román. Teatro Imagen. Santiago: CENECA, 1980. Impreso. 
Hurtado, María de la Luz y Mauricio Barría. Eds. Un siglo de dramaturgia chilena, 1910-2010. Tomo III: 1973-1990, Creatividad y resistencia en tiempos adversos. Santiago: Comisión Bicentenario, 2010. Impreso.

Husson, Roland. Nos duele Chile. Santiago: Cuarto Propio, 2010 [2003]. Impreso.

Meza, Gustavo. Murmuraciones acerca de la muerte de un juez y otras dos murmuraciones. Santiago: LOM, 1995. Impreso.

Mierda mierda, la función debe continuar. Dir. Daniel Uribe. Inteligencia Colectiva, Televisión Nacional de Chile. 2020. Serie documental. https://www.youtube.com/watch?v=ChMP907zZv0\&t=83s

Parra, Marco Antonio de la. Obscenamente (in)fiel o una personal crónica de mi prehistoria dramatúrgica / La secreta obscenidad de cada día / Infieles. Santiago: Planeta, 1988. Impreso.

---. "Prólogo. Por qué hay que leer a Gustavo Meza". Murmuraciones acerca de la muerte de un juez y otras dos murmuraciones. Santiago: LOM, 1995. 5-7. Impreso.

---. El arte del peligro. Santiago: Frontera Sur, 2007. Impreso.

Piña, Juan Andrés. "Prólogo. Resplandores y fracasos en las historias de Luis Rivano". Antología de obras teatrales. Santiago: RIL. 2008. 7-17. Impreso.

Radrigán, Juan. Crónicas del amor furioso. Santiago: Frontera Sur, 2004. Impreso.

Rivano, Luis. Antología de obras teatrales. Santiago: RIL. 2008. Impreso.

Rojo, Grínor. Muerte y resurrección del teatro chileno, 1973-1983. Madrid: Michay, 1985. Impreso.

Un diplomático francés en Santiago. Dir. Patricio Paniagua. Azul Producciones, Le Films du Tamarin. $2008 . \quad$ Largometraje documental. https://www.youtube.com/watch?v=RjSgLQDUKDw

Williams, Raymond. Cultura y sociedad, 1780-1950: De Coleridge a Orwell. Buenos Aires: Nueva Visión, 2001 [1958]. Impreso.

---. Marxismo y literatura. Barcelona: Península, 1997 [1977]. Impreso.

Recibido: 01 de Noviembre de 2021

Aceptado: 07 de Diciembre de 2021 